\title{
Evaluating the Concentration of Cotinine, Lead and Cadmium in Newborns with Respsiratory Distress Syndrome
}

\author{
Hiba Hussein Ali ${ }^{1}$, Ali Faris Hassan ${ }^{2}$, Hayder Hussein Alzubaidi ${ }^{3}$ \\ ${ }^{I}$ Pharmacist. Department of Toxicology/Medico Legal Directorate/Iraq, ${ }^{2}$ Lec. Dr. Departments of Pharmacology \\ and Toxicology / College of Pharmacy / University of Baghdad/Iraq, ${ }^{3}$ F.I.C.M.S Pediatrician, Al-Elwayia Pediatric \\ Teaching Hospital/Iraq
}

\begin{abstract}
Background Respiratory distress syndrome is one of the most common problems of newborns. Respiratory distress syndrome occurs when there is no enough surfactant in the lungs. Heavy metals are naturally occurring elements that have a high atomic weight and a density at least 5 times greater than that of water. Lead is a heavy metal, it is important environmental toxicant; the toxic effects of lead include many systems in the body like central and peripheral nervous system. Cadmium is heavy metal that exerts toxic effects on the kidney, the skeletal and the respiratory systems, and is classified as a human carcinogen. Nicotine, the main alkaloid of tobacco. It is readily absorbed from tobacco smoke, and its concentration rises over 6-8 hours during the day in regular smokers. About 70 to $80 \%$ of nicotine is metabolized to cotinine. Methods The study was carried out for 50 newborns divided in two groups: Group 1: 25 newborns with respiratory distress syndrome. Group 2: 25 newborns without respiratory distress syndrome. Results According to Demographic characteristics there are no significant differences when compered the age, gender, duration of pregnancy and the age of the mothers of newborns with respiratory distress syndrome and normal newborns $(p<0.05)$. the whole blood lead and serum cotinine concentration in newborns with respiratory distress syndrome was significantly higher compering with normal newborns $(p<0.05)$. The whole blood cadmium concentration in newborns with respiratory distress syndrome was not significantly different comparing with normal newborns $(p<0.05)$. Conclusions Newborns with respiratory distress syndrome have high serum level of cotinine and whole blood lead when compared to healthy newborns.
\end{abstract}

Keywords: Cadmium, cotinine, Heavy metals, Lead, Nicotine, Respiratory distress syndrome

\section{Introduction}

Respiratory distress syndrome (RDS), or hyaline membrane disease, is one of the most common problems of newborns. It can cause newborns to need extra oxygen and help to breathe ${ }^{(1)}$. Respiratory distress syndrome occurs when there is no enough surfactant in the lung. When there is not enough surfactant, the tiny alveoli collapse with each breath. As the alveoli collapse, damaged cells collect in the airways and further affect breathing ability. As the newborn's lung function decreases, less oxygen is taken in and more carbon

\section{Corresponding Author}

Hiba Hussein Ali

hussein.hiba@ymail.com dioxide accumulates in the blood. Signs and symptoms of RDS include: cyanosis, flaring of the nostrils, tachypnea, grunting sounds with breathing, chest retractions (2). RDS is usually diagnosed by chest X-rays of the lungs, blood gas tests and Echocardiography. (3) The multiple uses of heavy metals in industry, domestically, agriculturally, medically and technologically have led to their wide distribution in the environment ${ }^{(4)}$. Lead is a naturally occurring, present in small amounts in the earth's crust ${ }^{(5)}$. Exposure to lead and lead chemicals can occur through ingestion, inhalation and dermal contact, most human exposure to lead occurs through ingestion and inhalation ${ }^{(6)}$. Lead metal causes toxicity in living cells by ionic mechanism and that of oxidative stress. Antioxidants, e.g. glutathione, present in the cell protect it from free radicals such as $\mathrm{H}_{2} \mathrm{O}_{2}$. Under the influence of lead, however, the level of the ROS increases and 
the level of antioxidants decreases ${ }^{(7)}$. Cadmium (Cd) is a toxic heavy metal and the components of tobacco, together with water and food contamination, represent the main sources of non- occupational exposure in the general population. $\mathrm{Cd}$ enters the human body mainly after inhalation of environmental tobacco smoke and also via gastrointestinal absorption ${ }^{(8)}$. Continuous exposure to low levels of $\mathrm{Cd}$ may result in bioaccumulation and can cause a variety of adverse health effects on human beings, among which kidney function, lung diseases, and disturbed calcium metabolism and bone effects are the most prominent, depending upon the level and duration of exposure ${ }^{(9)}$.Cadmium increases the activity of some hydrolytic enzymes such as peroxidase that lead to intensifying the respiration of the cells and depletion of the cells nutrients during this process that leads to the acceleration of senescence ${ }^{(10)}$.

Nicotine, the main alkaloid of tobacco, is responsible for its addictive effect. About 70 to $80 \%$ of nicotine is metabolized to cotinine ${ }^{(11)}$. As the primary metabolite of nicotine, cotinine has been widely used as a specific biomarker of tobacco exposure because its half-life in the body (12-20 hours) is longer than that of nicotine (3-4 hours) ${ }^{(12)}$.

\section{Subjects and Methods}

\section{Research setting}

A cross sectional study of 50 newborn babies divided as follows:

1- Group 1: 25 newborns with respiratory distress syndrome (RDS). The newborns within this group were taken from Al-Elwayia Pediatric Teaching Hospital.

2- Group 2: 25 newborns without respiratory distress syndrome (RDS). The newborns within this group were taken from welfare pediatric Teaching Hospital- Medical city

The newborns were taken from both sexes, at the age range from 24 hours to one week. This study was conducted from the $1^{\text {st }}$ of March to the $30^{\text {th }}$ of July 2019

\section{Blood sampling:}

Approximately $(3 \mathrm{ml})$ of venous blood was taken from each newborn, which divided into three tubes:

- The first tube $(2 \mathrm{ml})$ whole blood is collected into EDTA tube for the measurement of blood levels of $\mathrm{Pb}$ and $\mathrm{Cd}$ by atomic absorption.

- The second tube $(0.5 \mathrm{ml})$ is collected in a gel tube from which immediately the serum was separated by centrifugation for the measurement of the concentration of cotinine by cotinine Elisa kit.

\section{Biochemical assay}

Frozen serum was allowed to thaw at room temperature; assessment of inorganic elements $(\mathrm{Pb})$ was performed by flame atomic absorption spectrophotometry (FAAS) ${ }^{(13)}$, while (Cd) was performed by graphite furnace atomic absorption spectrophotometry (GFAAS) (14).

\section{Statistical Analysis}

All the results were expressed as mean \pm standard deviation (SD). The data were analyzed by utilizing a computerized statistical package for the social sciences SPSS program. Unpaired Student t-test was performed for each group pair includes a comparison between two groups (P-values $<0.05)$ were considered to be statistically significant ${ }^{(15)}$. A chi-square test was used to assess the statistical significance in distribution between different discrete variables ${ }^{(16)}$.

\section{Ethical Consideration}

All administrative and Ethical approvals were taken from the parents, the administrative team of the hospital including the managing director, the head of the departments and collage of pharmacy- University of Baghdad.

\section{Results}

\section{Demographic Characteristics}

In table (1), according to the age of newborns, there is no significant difference in the age of RDS newborns when compare to the normal newborns $(p>0.05)$, the same finding was seen with the age of mothers in which there is no significant difference in age of mothers of RDS newborns when compared to the age of mothers of normal newborns $(p>0.05)$. The gender of RDS newborns was $18(72 \%)$ as a males and $7(28 \%)$ as females meanwhile the gender of normal newborns $15(60 \%)$ as males and $10(40 \%)$ as females. Regarding the duration of pregnancy, the duration of pregnancy of RDS newborns was not significantly differs from the duration of pregnancy of normal newborns $(p>0.05)$. 
According to the residency of newborns, the residency of RDS newborns and normal newborns were significantly different $(p<0.05)$, The residency of RDS newborns was $20(80 \%)$ live in urban area and 5(20\%) live in rural area meanwhile residency of normal newborns was 11(44\%) live in urban area and $14(56 \%)$ live in rural area.

According to the smoking status of newborns mothers, there are significant differences when comparing the smoking status of the mothers of RDS newborns and normal newborns $(p<0.05)$. The smoking status of RDS newborns mothers was found $0(0 \%)$ for non-smoking mothers, 23(92\%) for passive smoking mothers and $2(8 \%)$ for smoker mothers meanwhile the smoking status of normal newborns mothers was found $13(52 \%)$ for non-smoking mothers, $7(28 \%)$ for passive smoking mothers and 5(20\%) for smoker mothers.

According to the types of delivery of newborns, there are significant differences when comparing the types of delivery of RDS newborns and normal newborns $(p<0.05)$. The types of delivery of RDS newborns was found $9(36 \%)$ for a normal delivery and $16(64 \%)$ for caesarian delivery meanwhile the types of delivery of normal newborns was found $20(80 \%)$ for a normal delivery and 5(20\%) for caesarian delivery.

Table (1): Demographic characteristics of study groups

\begin{tabular}{|c|c|c|c|c|}
\hline & & RDS Newborns & Control Newborns & P-Value \\
\hline \multicolumn{2}{|c|}{ Age of newborns (days) } & $2.92 \pm 1.29$ & $3.04 \pm 1.24$ & 0.7378 \\
\hline \multirow{2}{*}{ Gender of newbor } & males & $18(72 \%)$ & $15(60 \%)$ & \multirow{2}{*}{0.3740} \\
\hline & females & $7(28 \%)$ & $10(40 \%)$ & \\
\hline \multicolumn{2}{|c|}{ Age of the mothers (years) } & $25.76 \pm 6.78$ & $26.44 \pm 5.75$ & 0.70415 \\
\hline \multicolumn{2}{|c|}{ Duration of pregnancy (weeks) } & $39.52 \pm 1.38$ & $39.48 \pm 1.87$ & 0.93203 \\
\hline \multirow{2}{*}{ Residency } & Urban & $20(80 \%)$ & $11(44 \%)$ & \multirow{2}{*}{0.00873} \\
\hline & Rural & $5(20 \%)$ & $14(56 \%)$ & \\
\hline \multirow{3}{*}{ Smoking status } & Non-smoking & $0(0 \%)$ & $13(52 \%)$ & \multirow{3}{*}{$1.1 * 10^{-5}$} \\
\hline & Passive smoking & $23(92 \%)$ & $7(28 \%)$ & \\
\hline & Smokers & $2(8 \%)$ & $5(20 \%)$ & \\
\hline \multirow{2}{*}{ Type of delivery } & Normal & $9(36 \%)$ & $20(80 \%)$ & \multirow{2}{*}{$8.4^{*} 10^{-7}$} \\
\hline & Caesarian & $16(64 \%)$ & $5(20 \%)$ & \\
\hline
\end{tabular}


Clinical Signs and Symptoms for RDS Newborns

In the table (2), the average duration of residency of RDS newborns in the hospital was (2.72 \pm 1.2 days), the average heart rate was $(159.19 \pm 1.77$ beats/mints $)$ and the average respiratory rate was $(77.56 \pm 3.25$ breath/ mints).

According to bell shape thorax, the number of RDS newborns with bell shape thorax was 13(52\%). According to grunting baby, number of RDS newborns with grunting was $9(36 \%)$. regarding to subcostal retraction, number of RDS newborns with subcostal retraction was $24(96 \%)$. Cyanosis was important sign for detecting the severity of RDS, number of RDS newborns with cyanosis was $12(48 \%)$.

The severity of RDS was categorized into three levels (mild-moderate - sever), newborns with mild RDS was $10(40 \%)$, and with moderate RDS was $7(28 \%)$ and with sever RDS was $8(32 \%)$.

Table (2). Clinical Signs and Symptoms for RDS Newborns

\begin{tabular}{|c|c|c|c|}
\hline & & $\begin{array}{l}\text { Clinical Sign and Symptoms for } \\
\text { RDS Newborns }\end{array}$ & Normal value \\
\hline \multicolumn{2}{|c|}{ Duration of residency in hospital (days) } & $2.72 \pm 1.2$ & \\
\hline \multicolumn{2}{|c|}{ Heart rate (beats/mint) } & $159.19 \pm 1.77$ & $120-160$ (beats/min) \\
\hline \multicolumn{2}{|c|}{ Respiratory rate (breaths/mint) } & $77.56 \pm 3.25$ & 30-60 (breaths/mint) \\
\hline \multirow{2}{*}{ Bell shape thorax } & Positive & $13(52 \%)$ & \\
\hline & Negative & $12(48 \%)$ & \\
\hline \multirow{2}{*}{ Grunting baby } & Positive & $9(36 \%)$ & \\
\hline & Negative & $16(64 \%)$ & \\
\hline \multirow{2}{*}{ Subcostal retraction } & Positive & $24(96 \%)$ & \\
\hline & Negative & $1(4 \%)$ & \\
\hline \multirow{2}{*}{ Cyanosis } & Positive & $12(48 \%)$ & \\
\hline & Negative & $13(52 \%)$ & \\
\hline \multirow{3}{*}{ RDS severity } & Mild & $10(40 \%)$ & \\
\hline & Moderate & $7(28 \%)$ & \\
\hline & Sever & $8(32 \%)$ & \\
\hline
\end{tabular}

\section{Whole blood Lead and Cadmium concentration}

In the table (3), according to whole blood lead concentration, the whole blood lead concentration in newborns with RDS was significantly higher when compared to the whole blood lead concentration in the normal newborns $(p<0.05)$. Both groups of a newborns have a blood lead concentration higher than normal value (Normal levels in newborn: $<10 \mu \mathrm{g} / \mathrm{dL}$ ) ${ }^{(17)}$. according to the whole blood cadmium concentration, whole blood cadmium concentration in newborns with RDS was not significantly differs when compared to the whole blood cadmium concentration in the normal newborns $(p<0.05)$. Both groups of a newborns have a blood cadmium concentration higher than normal value 
(Normal blood cadmium is $<0.005 \mu \mathrm{g} / \mathrm{mL}$ ) ${ }^{(17)}$.

Table (3) Whole blood Lead Concentration

\begin{tabular}{|l|l|l|l|}
\hline & RDS Newborns & Normal Newborns & P-value \\
\hline $\begin{array}{l}\text { whole blood lead } \\
\text { concentration }(\mu \mathrm{g} / \mathrm{dl})\end{array}$ & $16.36 \pm 3.1$ & $13.02 \pm 2.87$ & 0.0002411 \\
\hline $\begin{array}{l}\text { whole blood cadmium } \\
\text { concentration }(\mu \mathrm{g} / \mathrm{dl})\end{array}$ & $0.175 \pm 0.04$ & $0.165 \pm 0.03$ & 0.411070 \\
\hline
\end{tabular}

\section{Serum Cotinine Concentration}

In the table (4), according to serum cotinine concentration, serum cotinine concentration in newborns with RDS was significantly higher when compared to serum cotinine concentration in the normal newborns $(p<0.05)$. Both groups of a newborns have serum cotinine concentration higher than normal value (normal value of cotinine less than or equal to $10 \mathrm{ng} / \mathrm{mL})^{(18)}$.

Table (4). Serum Cotinine concentration

\begin{tabular}{|l|l|l|l|}
\hline & RDS Newborns & Normal Newborns & P-value \\
\hline $\begin{array}{l}\text { Serum cotinine concentration } \\
(\mathrm{ng} / \mathrm{dl})\end{array}$ & $93.16 \pm 5.16$ & $65.86 \pm 6.83$ & $7.28 * 10-21$ \\
\hline
\end{tabular}

\section{Discussion}

Respiratory distress syndrome (RDS) is a complex disease and several factors may contribute to its etiology. The incidence of RDS decreases with advancing gestational age, from about $60-80 \%$ in babies born at 26-28 weeks, to about $15-30 \%$ in those born at 32-36 weeks ${ }^{(19)}$. According to the table (1), male newborns with RDS were higher than the female newborns with RDS despite there were no significant differences between the sex when compare the healthy newborns and RDS newborns. This finding completely agrees with another previous study which found that male newborns are more likely than female newborns to develop RDS at ratio male-to-female ratio $(1.3: 1)^{(20)}$. These differences are thought to be partly due to androgenic actions on type II pneumocytes delaying the production of mature surfactant ${ }^{(21)}$. According to a table (1) the number of newborns with RDS who have a smoking mother or passive smoking higher than healthy newborns, this finding is compatible with previous studies which found that the cigarette smoking during pregnancy is associated with a decrease in the risk of RDS in very preterm babies ${ }^{(22)}$. In the present study, the newborns in both groups were at full term of gestation and it seems that the smoking of cigarettes loss its protective effect against RDS. According to a table (1) the number of newborns with RDS delivered by caesarian was higher than healthy newborns who delivered in a normal delivery. This finding completely matched with another previous study in which they found that at any given gestational age the incidence of RDS is greater for infants born by cesarean section, especially without established labor, than for those born by normal delivery ${ }^{(23)}$. In table (3), the concentration of lead in newborns with RDS was significantly differs comparing to healthy newborns. Lead is a well-known human reproductive toxin. For centuries, lead exposure has been linked to adverse outcomes in pregnant women and newborns (24). There is no previous study that links between RDS and blood lead concentration but there is a previous study for children showed that children with asthma 
were more likely to have 5-fold higher blood lead level $(>10 \mathrm{mg} / \mathrm{dL})$ than those without asthma. In table (4), the concentration of cadmium in newborns with RDS is not significantly differs comparing to healthy newborns. Short-term exposure to inhalation of cadmium can cause severe damages to the lungs and respiratory irritation while its ingestion in higher doses can cause stomach irritation resulting in vomiting and diarrhea. Long-term exposure to cadmium leads to its deposition in the bones and lungs. As such, cadmium exposure can cause bone and lung damage .

Ethical Clearance: The Research Ethical Committee at scientific research by ethical approval of both $\mathrm{MOH}$ and MOHSER in Iraq

\section{Conflict of Interest: Non}

FUNDING: Self-funding

\section{References}

1. Helve O, Pitkanen OM, Andersson S,O'Brodovich H, Kirjavainen T, Otulakowski G. Low expression of human epithelial sodium channel in airway epithelium of preterm infants with respiratory distress. Pediatrics. 2004;113(5):1267-1272.

2. Lista G, Castoldi F. Which clinical markers for appropriate timing of surfactant therapy? Acta Biomed. 2013;84(1):15-17.

3. Kurl S, Heinonen KM, Kiekara O. The first chest radio-graph in neonates exhibiting respiratory distress at birth. Clin Pediatr (Phila) 1997:285-9.

4. Duffus JH. Heavy metals-a meaningless term? Pure Appl Chem. 2002;74(5):793-807.

5. Jacobs DE, Clickner RP, Zhou JY, et al. The prevalence of lead-based paint hazards in U.S. housing. Environ Health Perspect. 2002;110: A599-A606.

6. Crce HQ. Lead toxicological overview, HPA 2012; 3(8):132-135.

7. Manay N, Cousillas AZ, Alvarez C, Heller T. Lead contamination in Uruguay: the "LaTeja" neighborhoodcase. Rev Environ ContamToxicol. 2008; 195:93-115.

8. Mortada WI, sobh MA. reference intervals of cadmium, lead and mercury in blood, urine, hair and nails among residents in Mansoura city, Nile Delta, Egypt Environment Res .2002;90;104.

9. Bazrafshan E, Edris B,Amir M, Simin N,et al .
Removal of cadmium from industrial effluents by electrocoagulation process using iron electrodes. Iran. J. Environ. Health. Sci. Eng., 2006; 3 (4): 261-266.

10. Beta I, Jana H, Ladislav T. Effect of cadmium on hydrolytic enzymes in maize rootand coleoptile, Biological journal 2004 ; (4):513-517.

11. Benowitz NL. Pharmacology of nicotine: addiction and therapeutics. Ann Rev Pharmacol Toxicol. 1996; 36: 597-613.

12. Benowitz NL, Cotinine as a biomarker of environmental tobacco smoke exposure. Epidemiol Rev. 1996; 18: 188-204.

13. Rehber T, Huseyin B, Baki E. Determination of iron and lead by flame atomic absorption spectrometry after preconcentration with sepiolite. Fresenius' Journal of Analytical Chemistry. 1997; 357(3): $351-353$.

14. Kim M. Determination of lead and cadmium in wines by graphite furnace atomic absorption spectrometry. Food Addit Contam. 2004;21(2):1547.

15. Yim KH, Nahm FS, Han KA, Park SY. Analysis of statistical methods and errors in the articles published in the korean journal of pain. Korean $J$ Pain. 2010; 23:35-41.

16. Scott M, Flaherty D, Currall J. Statistics: Dealing with categorical data. J Small Anim Pract. 2013; 54:3-8.

17. World Health Organization. Health risks of heavy metals from long range trans-boundary air pollution. Copenhagen: World Health Organization Regional Office for Europe; 2007. pp. 40-45.

18. Pirkle JL, Flegal KM, Bernert JT, Brody DJ, Etzel RA, Maurer KR. Exposure of the U.S. population to environmental tobacco smoke: The Third National Health and Nutrition Examination Survey, 19881991. JAMA 1996; 275:1233-40.

19. Stoelhorst GM, Rijken M, Martens SE, et al. Changes in neonatology:comparison of two cohorts of very preterm infants (gestational age less than 32 weeks): the Project On Preterm and Small for Gestational Age Infants 1983 and the Leiden Follow-Up Project on Prematurity 1996-1997. Pediatrics 2005; 115: 396-405.

20. Dani C, Reali MF, Bertini G, et al. Risk factors for the development of respiratory distress syndrome and transient tachypnoea in newborn infants. 
Italian Group of Neonatal Pneumology. Eur Respir J 1999; 14: 155-9.

21. Rodriguez A, Viscardi RM, Torday JS. Fetal androgen exposure inhibits fetal rat lung fibroblast lipid uptake and release. Exp Lung Res 2001; 27: 13-24.

22. Burguet A, Kaminski M, Truffert P, Menget A, Marpeau L, et al. Does smoking in pregnancy modify the impact of antenatal steroids on neonatal respiratory distress syndrome? Results of the Epipage study. Arch Dis Child Fetal Neonatal Ed. 2005; 90(1): F41-F45.
23. Bernard SM, McGeehin MA. 2003. Prevalence of blood lead levels $>$ or $=5$ micro g/dL among U.S. children 1 to 5 years of age and socioeconomic and demographic factors associated with blood of lead levels 5 to 10 micro g/dL, Third National Health and Nutrition Examination Survey, 1988-1994. Pediatrics 112(6 pt 1):1308-1313.

24. Zanardo V, Simbi AK, Franzoi M, Solda G, Salvadori A, Trevisanuto D. Neonatal respiratory morbidity risk and mode of delivery at term: influence of timing of elective caesarean delivery. Acta Paediatr2004; 93: 643-7. 